\title{
Editorial
}

\section{The Diamond Jubilee of the Nutrition Society}

In 2001 the Nutrition Society will celebrate the 60th anniversary of its formation. The Society was set up in 1941 by a forwarding-thinking group of UK scientists including physiologists, agricultural scientists, chemists and clinicians who came together to establish a scientific society dedicated to the pursuit of new knowledge in animal and human nutrition (Widdowson, 1980, 1991). The formation of the Nutrition Society, as well as providing a forum for the presentation and the dissemination of research findings, also lent essential scientific credibility to a subject that many regarded as not appropriate for serious academic enquiry. Since 1947 the British Journal of Nutrition has been the house journal of the Society and is recognised world-wide as one of the premier journals in nutrition. The composition of the editorial board, panel of referees and authorship of published papers attest to the international nature and standing of the journal. The Society has been very well served over many years by senior Editors of the highest academic standing who have worked tirelessly to establish and maintain the high standards of the journal. As well as its house journal, the Society also publishes a review journal, Nutrition Research Reviews, which provides timely and scholarly review papers. In 1998, the Society established the sister journal of the British Journal of Nutrition, the journal of Public Health Nutrition, in recognition of the need for an international journal dedicated to publication of research findings in this rapidly developing area. This journal has an excellent team of editors and has quickly established itself as a journal of repute, attracting high-impact papers.

Each year the Society hosts four to six scientific meetings with at least one of the meetings held in collaboration with another scientific organisation or another European nutrition society. The Nutrition Society publishes the output from its meetings in the Proceedings of the Nutrition Society, which is extensively cited for its outstanding plenary and symposium papers. The Society has been particularly encouraged by the success of meetings jointly organised with other European societies, including meetings held recently in Nancy, France (1998) and Pamplona, Spain (1999). Our members from low-income countries provide an important international context for our meetings and continue traditional links established between the Society and the developing countries many years ago. International links are further strengthened by the collaborations achieved through our membership of International Union of Nutritional Sciences (IUNS) and of Federation of European Nutritional Sciences (FENS), which are highly valued. In 2001 the Nutrition Society will participate in the IUNS meeting in Vienna, Austria and is already in active discussion with the organisers of the FENS meeting to be held in Italy in 2003.

In the last few years the Society has begun to expand its educational and professional activities. In late 2001, the Society, supported by a team of editors from Europe, USA and the UK, will launch the publication of a series of four textbooks in nutrition, designed to meet the needs of undergraduate and postgraduates in nutrition and related subjects. The Society, along with its sister societies in Europe and USA, has also recognised threats to the credibility of the subject that arise from the use of the title of nutritionist by unqualified and sometimes bogus practitioners. The Society has taken a pro-active role in this area, establishing a Register of Nutritionists and Public Health Nutritionists and accrediting undergraduate and postgraduate courses in public health nutrition. Ultimately, it is hoped that these activities will allow the Society to establish protection of the title of nutritionist. In these activities senior members of the Society have worked closely with colleagues from mainland Europe to ensure a coordinated approach to the development of public health nutrition and the protection of the discipline.

It is clear that both scientific and socio-political influences were profoundly important in establishing nutrition as a reputable scientific discipline in the middle of the 20th century. The extraordinary progress and discoveries made in nutrition between 1900 and 1940, including the nature and biochemical roles of the essential amino acids, the vitamins, minerals and essential fatty acids as well as basic facts on the nutrient compositions of everyday foods, provided the scientific basis of the discipline. Recognition of the vital importance of diet to health led to implementation of public health policies that made great impact on the nutrition and well-being of ordinary people. However, it is unlikely that the scientific advances of the early part of the century would have made such a large or immediate impact had it not been for the advent of the second World War, which required the government of the day to take a serious look at the nutritional needs of the population and particularly those of its most vulnerable groups. The UK Government brought together scientists working in disparate disciplines of biochemistry, agriculture and food composition, as well as clinicians experienced in nutrition, to help them plan the wartime diet. It was this collective activity that sparked the recognition that not only did their separate disciplines have much in common, but a scientific society representing this multi-disciplinary base was needed to maintain the collaborations and to disseminate the science outside the UK community. 
Today we do not have the 'benefit' of wartime pragmatism to encourage scientific collaboration and facilitate public health strategy and practice. Nevertheless, it is clear that within the UK, and on a wider global basis, much could be gained through greater collective activity that could channel present scientific knowledge and sociopolitical circumstances to the best advantage of our science and to society as a whole. Clearly the nutritional problems of today appear on initial examination to be very different from those of 1941. In most highly-developed countries, deficiency diseases are virtually unknown, whereas the increased prevalence of CHD, diabetes, obesity and some forms of cancer have been attributed to excessive consumption of some nutrients and low levels of physical activity. Nevertheless, given evidence for protective roles of folic acid, dietary antioxidants and other phytoprotectants in these diseases, it would be a gross simplification to describe our present problems simply as those of overnutrition. Until we have a better understanding, at a molecular level, of how dietary components and nutritional factors contribute to the pathophysiology of these diseases, the degree of certainty with which we can provide public health advice will be much less than that provided by wartime scientists.

There is no doubt that nutrition scientists have yet to exploit the new developments in molecular biology to their fullest extent (Trayhurn, 1998). There is a particular need to conduct integrated studies that evaluate effects of dietary components at the cellular, tissue and whole-animal levels. To do this will require not just investment in people and infrastructure, but also greater multi-disciplinary collaboration on a global scale. Indeed, many believe that the widespread application of molecular biology is destined to break down the barriers between bioscience disciplines, reversing a 'separatist' trend that has been dominant since after the war.

The Society's journals play a vital role in disseminating advances in nutrition science on a global basis and particularly so with the advent of electronic publishing which is destined to revolutionise scientific communications. Recent editors of the British Journal of Nutrition have been extremely responsive to many of the challenges posed by the globalisation of our science and have done much to expand the international scope of the journal. Their evident success is represented in the quality and content of the present issue. The Nutrition Society supports the Editorin-Chief in his continued determination to publish work of the very highest standard and which reflects the diversity of nutrition science in the UK, Europe and worldwide. Whilst our founder members might be pleased to see retention of 'British' in the British Journal of Nutrition, they would be even better pleased by the current content and global scope of the journal.

Christine M. Williams President of the Nutrition Society

\section{References}

Widdowson EM (1980) Adventures in nutrition over half a century. Proceedings of the Nutrition Society 39, 293-306.

Widdowson EM (1991) The Nutrition Society 1941-1991. Presidents and Honorary Members: Their Stories and Recollections. Wallingford: BAC International.

Trayhurn P (1998) Molecular biology and nutrition: the quest for integration. British Journal of Nutrition 80, 305-306. 